\title{
Recent advances in carbon nanotube-based enzymatic fuel cells
}

\author{
Serge Cosnier ${ }^{1,2}$, Michael Holzinger ${ }^{1,2}$ and Alan Le Goff ${ }^{1,2}$ \\ 1 Département de Chimie Moléculaire (DCM) UMR 5250, Université Grenoble Alpes, Grenoble, France \\ 2 Département de Chimie Moléculaire (DCM) UMR 5250, CNRS, Grenoble, France
}

\author{
Edited by: \\ Uwe Schröder, Technische Universität \\ Braunschweig, Germany \\ Reviewed by: \\ Shelley Minteer, University of Utah, \\ USA \\ Sven Kerzenmacher, University of \\ Freiburg, Germany \\ *Correspondence: \\ Serge Cosnier, DCM UMR 5250, \\ CNRS, Université Grenoble Alpes, \\ 570 Rue de la Chimie, BP 53F-38041 \\ Grenoble Cedex 9, France \\ e-mail: serge.cosnier@ujf-grenoble.fr
}

This review summarizes recent trends in the field of enzymatic fuel cells. Thanks to the high specificity of enzymes, biofuel cells can generate electrical energy by oxidation of a targeted fuel (sugars, alcohols, or hydrogen) at the anode and reduction of oxidants $\left(\mathrm{O}_{2}, \mathrm{H}_{2} \mathrm{O}_{2}\right)$ at the cathode in complex media. The combination of carbon nanotubes (CNT), enzymes and redox mediators was widely exploited to develop biofuel cells since the electrons involved in the bio-electrocatalytic processes can be efficiently transferred from or to an external circuit. Original approaches to construct electron transfer based CNT-bioelectrodes and impressive biofuel cell performances are reported as well as biomedical applications.

Keywords: biofuel cells, biobatteries, enzymes, nanostructured carbon, modified electrodes, carbon nanotubes, enzyme wiring, laccase

\section{INTRODUCTION}

The electrical powering of billions of electronic gadgets like cell phones or computers leads to the production of a countless number of lithium batteries in the environment creating a real problem for human health. Moreover, the ever-increasing depletion of fossil fuels and the need for clean methods of producing electricity have stimulated the emergence of new sources of sustainable and renewable energy without greenhouse gas emissions or environmental pollution. Among these clean alternative sources, the production of electrical energy thanks to biofuel cells, a subcategory of fuel cells, is a rapidly growing field. In particular, enzymatic fuel cells that convert chemical energy into electrical energy by catalytic reaction of the enzymes, is one of the most common and studied configuration (Barton et al., 2004; Cracknell et al., 2008; Zayats et al., 2008; Willner et al., 2009; Ivanov et al., 2010; Leech et al., 2012; Katz and MacVittie, 2013; Cosnier et al., 2014). These biofuel cells use redox enzymes for the specific oxidation of fuels (alcohols, hydrogen, lactate, sugars such as glucose, fructose, lactose, or cellobiose) at the anode and the reduction of oxidizers $\left(\mathrm{O}_{2}, \mathrm{H}_{2} \mathrm{O}_{2}\right)$ at the cathode in order to generate electric power (Meredith and Minteer, 2012). A vast majority of these biofuel cells produce electric power from the electro-enzymatic degradation of glucose and oxygen. Compared to hydrogen or methanol fuel cells, sugars like glucose present the unique advantage of being a perfect energy storage compound in many living organisms and have absolutely no toxicological, explosive or flammable risks. Taking into account that catalysts, fuels, and products are biodegradable, the inherent ecological aspect of the biofuel cells compared to fuel cells should be noted. Fuel cells require catalysts based on precious metals or transition metals such as nickel, gold, silver, rhodium, ruthenium, palladium or chromium, or alloys such as Raney nickel (Zhang, 2008).

The main application of biofuel cells is to design devices whose power and size will be compatible with a use as portable source of energy (miniature generators of low power for mobile phone or GPS). Combined with conventional batteries, these biosystems will also be able to ensure a recharging of the batteries and a standby mode for electronic equipment. Owing to the presence of some fuels such as glucose and lactate in physiological fluids, another major motivation for the development of biofuel cells concerns the production of electricity from human body. Two approaches are in constant development: enzymatic fuel cells implanted in the body and using glucose present in the blood or interstitial fluids and non-invasive fuel cells using lactate present in human perspiration. The objectives are for the former to power implanted medical devices like cardiac pacemakers, muscle stimulators, neurological stimulators, cochlear implants, drug pumps, sensors, while those for the latter are to harvest energy from human for powering wearable electronics (Jia et al., 2013; Katz and MacVittie, 2013; Cosnier et al., 2014).

Although the first example of a biofuel cell has been reported in the 60s (Yahiro et al., 1964), the development of such promising devices has remained scarcely investigated until the late $90 \mathrm{~s}$. Since the early 2000s, tremendous advances have been achieved in the field of biofuel cells as evidenced by the exponential increase of scientific publications devoted to this topic. This results from the removal of technological barriers directly related to profound progress made in the field of electrochemical biosensors like the design of new materials and procedures for immobilization and electrical connection of enzymes (Polsky et al., 2001; Ronkainen et al., 2010; Samanta and Sarkar, 2011).

In particular, the development of biointerfaces has triggered enormous attention in the field of energy conversion. Taking into account that the bioelectrode activity was related to the activity of the wired enzymes, three-dimensional structures were designed to enhance the specific surface of the conductive substrate and the immobilized amount of enzymes and redox mediators serving as electron shuttle between enzymes and the electrode surface. In 
this context, numerous efforts have been focused in the production of novel biomaterials based on aerogels (Wen et al., 2014), osmium-derivatized polymers (Shaoa et al., 2014), redox hydrogels (Flexer and Mano, 2014; Plumeré et al., 2014), inorganic clays (Zebda et al., 2011a), and conductive nanomaterials (Willner et al., 2006; Holzinger et al., 2012). For instance, deposited hydrogel films based on osmium-containing metallopolymer that are permeable to water-soluble chemicals, were widely employed by Mano's and Heller's group for designing enzymatic fuel cells. These conducting polymer hydrogels were thus applied to the entrapment of enzymes (glucose oxidase, glucose dehydrogenase, bilirubin oxidase, laccase) onto platinum microelectrodes and nanostructured scaffolds of carbon fibers grown by chemical vapor deposition (Soukharev et al., 2004; Little et al., 2011; Flexer et al., 2013). In addition, the modulation of the tethering of redox centers to the polymer backbone was investigated for optimizing the enzyme wiring (Forster et al., 2003). Moreover, the stabilization of the bioarchitectures was envisioned by photoinitiated polymerization of poly(ethylene-glycol) diacrylate as outer layer (Suraniti et al., 2011).

Owing to the intense research activity in this field, we aim not to give a complete coverage of biofuel cells literature involving $3 \mathrm{D}$ constructs, but rather to review briefly the recent strategies employed with carbon nanotubes (CNT) for enzyme immobilization and their wiring.

\section{ENZYMATIC FUEL CELLS BASED ON CARBON NANOTUBE DEPOSITS}

Within the vast number of available nanostructured materials and nano-objects, CNTs exhibit, between others, nanowire morphology, biocompatibility, and excellent conductivity (Dai, 2002; Smart et al., 2006). Due to their geometry, CNT presents an impressive high specific surface of more than $1000 \mathrm{~m}^{2} / \mathrm{g}$ constituting thus an attractive building block for the construction of highly porous three-dimensional nanostructured CNT electrodes (Peigney et al., 2001). These particularities confer to nanotubes a pivotal role for designing electrochemical biosensors and biofuel cells. Furthermore, the possibility to add appropriate functionalities via organic functionalization enabled optimal tuning of such nanostructured electrodes by attaching specific (redox) sites for fixing proteins or catalyzing electrochemical reactions with enzymes or coenzymes.

In this context, CNTs have played an important role for interfacing enzymes with electronic circuitry. In particular, these CNT can establish an electrical communication with enzymes via their intrinsic conductivity or via an electron transport to enzymes ensured by electron hopping between immobilized redox centers. With regard to their nanoscale size, CNTs can approach in close proximity the prosthetic site of enzymes and hence achieve a direct electrical wiring between enzymes and the bulk electrode (Figure 1). As a consequence, electrodes modified by CNTs have aroused widespread attention in the design of biofuel cells (Holzinger et al., 2012).

A significant step in the development of bioelectrodes was thus described in 2010 by Cosnier and coworkers who have patented a new approach to create "ex nihilo" bioelectrodes by compressing a powder mixture of CNT and enzyme (Cosnier et al., 2010). This method of bioelectrode fabrication that leads to mechanically stable disks was applied to the development of glucose biofuel cells. The compression of CNTs with glucose oxidase and laccase enables direct electron transfer (DET) between the enzymes and the CNT matrix thus shuttling the involved electrons of the oxidation of glucose and the reduction of oxygen to an external circuit. The resulting mediatorless enzymatic fuel cell delivered a remarkable high open-circuit voltage $(0.95 \mathrm{~V})$ and an impressive maximum power density of $1.25 \mathrm{~mW} \mathrm{~cm}^{-2}\left(1.66 \mathrm{~mW} \mathrm{~mL}^{-1}\right.$, $1.85 \mathrm{~mW} \mathrm{~g}^{-1}$ ) and $0.14 \mathrm{mWh} \mathrm{cm}^{-2}$ under continuous discharge in a $50 \mathrm{mmol} \mathrm{L}^{-1}$ glucose solution (Zebda et al., 2011b). Surprisingly, it appears that the glucose biofuel cell performance

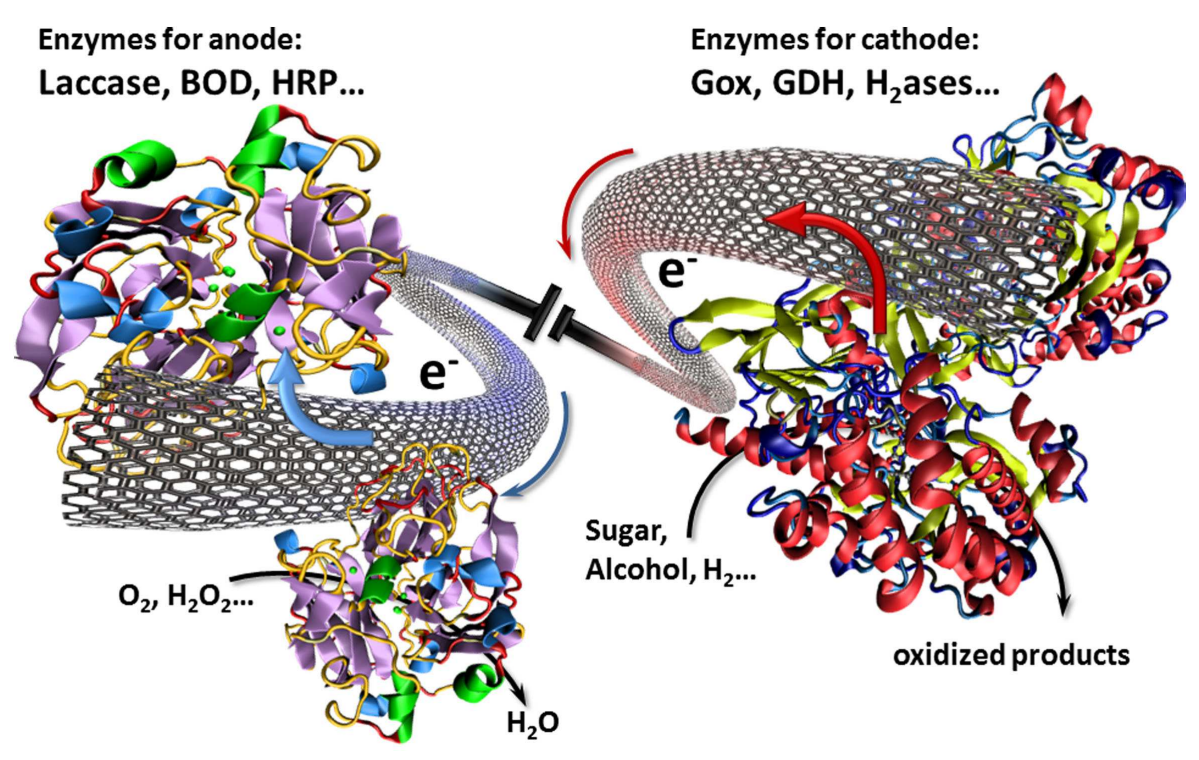

FIGURE 1 | Illustration of a biofuel cell setup using CNTs as nanowires for the transfer of electrons involved in the electrocatalytic redox reactions. 
is limited by the bioanode although the glucose concentration was markedly higher than that of $\mathrm{O}_{2}$. This phenomenon may be ascribed to a more efficient electrical wiring of laccase than glucose oxidase, which has its redox active prosthetic groups deeply located inside the protein shell. The occurrence of a DET process at the bioanode was investigated by cyclic voltammetry experiments. In the absence of glucose, a reversible system was observed at E1/2 $=-0.46 \mathrm{~V}$ vs. SCE (Reuillard et al., 2013). The latter was attributed to the electroactivity of the FAD, the prosthetic group of glucose oxidase. In addition, a weak electrocatalytic anodic current appeared in presence of glucose $(150 \mathrm{mM})$. However, the origin of this system remains questionable and could be due to a partial opening of the protein, the stability of this redox signal eliminating the assumption of a total release of the FAD from the protein. The weak intensity of the glucose oxidation at this potential $(-0.4 \mathrm{~V})$ reflects that only few CNTs could get in sufficient close contact to glucose oxidase by this compression method, to regenerate the enzyme and hence, a low percentage of the immobilized glucose oxidase was efficiently connected. As a consequence, a new configuration of compressed bioanode based on mixed DET and mediated electron transfer (MET) was reported. The concept is based on simple addition of naphthoquinone as redox mediator to the glucose oxidase/CNT mixture before compression, leading to its immobilization within the resulting disk. Thanks to its small size, this redox mediator serves as electron shuttle capable to collect the electrons from the glucose oxidase and to transfer them to the CNT matrix. By using the same biocathode, the power density of the completed biofuel cell increased to $1.54 \mathrm{mWcm}^{-2}\left(1.92 \mathrm{~mW} \mathrm{~mL}^{-1}, 2.67 \mathrm{~mW} \mathrm{~g}^{-1}\right)$ reflecting thus an improved wiring of the entrapped enzymes (Reuillard et al., 2013). This biofuel cell setup with the modified bioanode is also able to constantly deliver $0.56 \mathrm{mWh} \mathrm{cm}^{-2}$ under long-term discharge. Owing to the high amount of immobilized glucose oxidase, an attractive storage stability of the enzymatic fuel cell stored in phosphate buffer at room temperature was observed, the open-circuit voltage decreasing from 0.76 to $0.5 \mathrm{~V}$ after 6 months.

For the electrochemical storage of energy, CNTs are often employed as basis material for the construction of high performance supercapacitors with extremely short charging time and high capacitance. The latter can act as the bridge between batteries and conventional capacitors due to their properties to store high energy densities combined with rapid charge/discharge cycles. As a consequence, compressed disks of enzymes-CNTs were used as supercapacitors and electrodes for a biofuel cell setup. It was expected that the possibility to recharge supercapacitors with an internal energy source could thus represent a significant improvement for the performance of biofuel cells. This hybrid supercapacitor/biofuel cell enables high-power discharge cycles, the CNT disks being continuously recharged through the biocatalytic energy conversion in neutral buffered glucose solutions (Agnès et al., 2014). In addition, this hybrid device presents an attractive operational stability delivering 40,000 constant pulses of $2 \mathrm{~mW}$ for $10 \mathrm{~ms}$ every $10 \mathrm{~s}$ at least for 5 days.

On the other hand, CNTs can form flexible and high conductive sheets called buckypapers. Among different ways to form buckypapers, the most common approach is vacuum filtration of CNT dispersions where important factors are the purity and the graphitization of CNT and their homogeneous dispersion. For instance, efficient biocathodes for biofuel cells were prepared by adsorbing laccase on multiwalled CNTs buckypaper fabricated by dispersion in water and filtration on nylon membrane filter. These bioelectrodes catalyze the reduction of oxygen with an opencircuit potential of $0.64 \mathrm{~V}$ vs. SCE providing a current density of about $0.43 \mathrm{~mA} \mathrm{~cm}^{-2}$ at $0.5 \mathrm{~V}$ (Hussein et al., 2011). However, commercial mass produced multiwalled CNTs generally have highly defective outer walls, which prevent the formation of buckypapers without additives (Zhang et al., 2013). To overcome these issues, an innovative approach lies in the crosslinking of CNTs by organic spacers bearing several specific groups capable of generating covalent or non-covalent bonds with CNT walls. In particular, the non-covalent modification of CNT coatings was attempted with pyrene derivatives enabling $\pi$-stacking interactions with CNT wall. Buckypaper electrodes with enhanced mechanic stability were formed using a classical filtration technique of a CNT suspension in presence of a bis-pyrene crosslinker containing the redox mediator 2,2'-Azino-bis(3-ethylbenzothiazoline-6-sulfonic acid (ABTS) (Bourourou et al., 2014). Beside the formation of reinforced buckypaper, this bis-pyrene-ABTS assures the MET to laccase. The resulting buckypaper electrodes were thus applied to oxygen reduction using laccase in solution. For this setup, the redox buckypaper electrodes demonstrate high performances with maximum currents up to $1 \mathrm{~mA} \mathrm{~cm}{ }^{-2} \pm 40 \mu \mathrm{A} \mathrm{cm}^{-2}$. Buckypaperbased biocathodes were designed for air-breathing conditions using laccase or bilirubin oxidase as catalysts reaching up to $755 \pm 39 \mathrm{~mA} \mathrm{~cm}^{-2}$ at $0.3 \mathrm{~V}$ vs. $\mathrm{Ag} / \mathrm{AgCl}$ (Babanova et al., 2014) and $0.5 \mathrm{~mA} \mathrm{~cm}^{-2}$ at zero potential vs. $\mathrm{Ag} / \mathrm{AgCl}$ (Lau et al., 2012), respectively.

\section{NEW ADVANCES IN BIOCATHODES BASED ON CNT CONSTRUCTS FOR OXYGEN REDUCTION}

While sugars and alcohols can reach sufficient molar concentrations in water, the low concentration of oxygen may be a limiting factor for the performances of the enzymatic fuel cell. Over the past several years, we have witnessed an exponential growth in publications on optimizing biocathodes mainly based on laccase for oxygen reduction. For instance, among various techniques employed to entrap laccases in CNT matrices, an original waterinduced shrinkage of a free-standing MWCNT-forest film has shown remarkable performances for the enzyme entrapment and the direct wiring of laccases (Miyake et al., 2011a). Taking into account that laccase exhibits a hydrophobic cavity near its peripheral $\mathrm{T} 1$ copper center, the possibility to orientate and to wire this enzyme during its immobilization may increase the electron transfer rate, and therefore, the catalytic current. This hydrophobic domain even leads to spontaneous oriented adsorption on carbon electrodes. Rubenwolf et al. took advantage of this effect and designed a buckypaper-based cathode where the catalyst could be renewed by changing the enzyme containing electrolyte where clearly enhanced biocathode lifetimes could be reached (Rubenwolf et al., 2012). The efficiency of this principle for lifetime elongation was confirmed with multicopper enzyme containing crude fungal culture supernatants (Sané et al., 2013). Similarly, multicopper oxidases from enzyme-secreting recombinant planktonic 
microorganisms have been used, though with these a lifetime elongation has not yet been (Sané et al., 2014).

Furthermore, the Armstrong's group has modified electrodes with aryldiazonium derivatives having $\pi$-extended hydrophobic groups such as anthraquinone, anthracene, naphthalene, or chrysene to graft and connect laccase (Blanford et al., 2009). Several examples report the efficient immobilization, orientation, and wiring of laccase using polyaromatic hydrocarbons such as anthracene or naphthalene (Meredith et al., 2011). More recently, the ability of anthraquinone to immobilize and orientate laccase was optimized using a bis-anthraquinone-pyrene derivative whose geometry only authorizes a partial $\pi$-stacking on CNTs facilitating thus the laccase binding (Bourourou et al., 2013). The use of CNT-based electrodes allows the achievement of high catalytic currents of more than $1 \mathrm{~mA} \mathrm{~cm}^{-2}$. Another strategy consists in functionalizing CNTs by electrochemical polymerization of organic films. An electrogenerated poly(pyrrole-pyrene) allows thus the covalent immobilization of laccase via its interaction with polymerized pyrene, leading to a high performance biocathode with a catalytic current density of $1.85 \mathrm{~mA} \mathrm{~cm}^{-2}$ at $0.3 \mathrm{~V}$ (vs. SCE) in oxygen-saturated solution. In addition, these electrodes showed also excellent stabilities under continuous discharge (Lalaoui et al., 2013) (Figure 2).

\section{ENZYMATIC FUEL CELLS HARVESTING ENERGY FROM LIVING ORGANISMS}

Taking into account that glucose and lactate are present in many living organisms, some biofuel cells were designed for harvesting energy from fruits, small insects, and animals. The main configurations of enzymatic fuel cells involved bioanodes based on glucose oxidase, glucose dehydrogenase, or lactate oxidase and biocathodes based on copper oxidases such as laccase, tyrosinase, or bilirubin oxidase. This concept was initiated by Mano et al. who implanted microbioelectrodes based on osmium redox hydrogels, in a grape obtaining thus $2.4 \mu \mathrm{W}$ at $0.54 \mathrm{~V}$ (Mano et al., 2003). In 2010, the first example of an enzymatic fuel cell totally

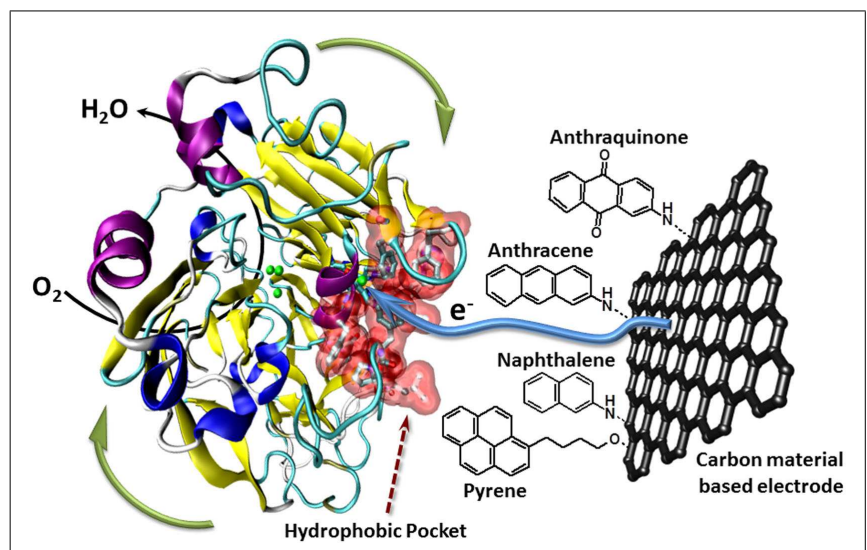

FIGURE 2 | Schematic presentation of the oriented immobilization of laccase via supramolecular interactions between the laccase's hydrophobic pocket and polyaromatic hydrocarbons like anthraquinone, anthracene, nathpthalene, or pyrene attached to carbon material based electrodes. implanted in a mammal (inside the retroperitoneal space of a rat) was described (Cinquin et al., 2010). This biofuel cell was based on compressed graphite-based disks entrapping redox mediators and tyrosinase and glucose oxidase at the cathode and anode, respectively. Although this work demonstrated the possibility of harvesting energy by a biofuel cell implanted inside a mammal, the open-circuit voltage and power density were far below the levels required to supply implanted biomedical devices. Different examples of biofuel cells partially implanted in the abdomen of an insect (a cockroach species) (Rasmussen et al., 2012) or directly in blood in a vein of a rabbit (Miyake et al., 2011b) or in the jugular vein of a rat (Sales et al., 2013) were more recently reported. However, these biofuel cells did not show sufficient performance to power electronic systems. Nevertheless, Mao and coworkers presented an original concept where a glucose biofuel cell itself acts as sensor to monitor the glucose concentration in vivo. Here, the output cell voltage is related to the glucose concentration of the rat's brain fluid, conducted through an external microfluidic circuit (Cheng et al., 2013).

With the aim to improve the performance of the implanted enzymatic fuel cells and, contrarily to the initial concepts, researchers conceived biofuel cells based on CNT. Thus buckypaper electrodes composed of compressed multiwalled CNT were modified by pyrene-butanoic acid via $\pi$-stacking interactions. These functionalized buckypapers were subsequently functionalized by chemical grafting of PQQ glucose dehydrogenase at the bioanode and laccase at the biocathode enabling a DET between enzyme and CNT electrodes. The validity of this approach was initially demonstrated through the implantation of biofuel cell in snail and more recently on the surgically exposed cremaster tissue of a rat (Halámková et al., 2012; Andoralov et al., 2013). Similar enzyme-buckypaper electrodes were employed for biofuel cells implanted in clams and lobsters connected in series (Szczupak et al., 2012; Southcott et al., 2013). Although lobsters are crustaceans, which are arthropods and are therefore distant from mammals, this work represents a breakthrough in the field of biofuel cells by demonstrating that an implanted biofuel cell can harvest enough energy from the compounds present in physiological fluids to power a pacemaker, an electrical motor, or a watch. As demonstrated by the Katz's group, the biofuel cell voltage is limited but its interfacing with microelectronic circuits can lead to devices that can deliver a voltage of several volts. Beside this, a biofuel cell based on compressed CNT-enzymes disks and wrapped in dialysis bag and Dacron bag, was successfully implanted by surgical insertion into the retroperitoneal space of rats. This biofuel cell delivered in vivo an open-circuit voltage of $0.85 \mathrm{~V}$. These measurements show that using a step-up converter circuit, the biofuel cell was able to power in physiological conditions, a Light Emitting Diode and a thermometer (Zebda et al., 2013). However, the development of implanted biofuel cells must meet the criteria of biocompatibility, sterilization, and long operational stability. The insertion of a biofuel cell in animals and in particular human bodies requires invasive and strict procedures. In this context, another strategy exemplified by Wang's group, lies in the development of non-invasive biofuel cells that can harvest energy from metabolites present on the epidermis or even in subcutaneous level (Jia et al., 2013; Valdés-Ramírez et al., 2014). 


\section{CONCLUSION}

Despite impressive results in energy harvesting using sugars and oxygen as fuels, further progress is needed as this technology becomes competitive with lithium batteries, which are currently used for electronic devices. For example, the state of the art fuel cell glucose normally offers several hundred microwatts up to few milliwatt at about $0.4-0.5 \mathrm{~V}$ with stabilities up to several weeks. This is not sufficient to power electronic devices without step-up converters. Nevertheless, owing to the wide range of available additives, all with their own specific properties, it clearly appears that the combination of various compounds (polymers, nanoparticles, redox mediators, crosslinking agents) with CNTs in various forms (buckypaper, pellets, forest, etc.) is a promising way to increase the performances of enzymatic fuel cells.

\section{REFERENCES}

Agnès, C., Holzinger, M., Le Goff, A., Reuillard, B., Elouarzaki, K., Tingry, S., et al. (2014). Supercapacitor/biofuel cell hybrids based on wired enzymes on carbon nanotube matrices: autonomous reloading after high power pulses in neutral buffered glucose solutions. Energy Environ. Sci. 7, 1884-1888. doi:10.1039/ C3EE43986K

Andoralov, V., Falk, M., Suyatin, D. B., Granmo, M., Sotres, J., Ludwig, R., et al. (2013). Biofuel cell operating in vivo in rat. Electroanalysis 25, 1579-1584. doi:10.1002/elan.201300136

Babanova, S., Artyushkova, K., Ulyanova, Y., Singhal, S., and Atanassov, P. (2014). Design of experiments and principal component analysis as approaches for enhancing performance of gas-diffusional air-breathing bilirubin oxidase cathode. J. Power Sources 245, 389-397. doi:10.1016/j.jpowsour.2013. 06.031

Barton, S. C., Gallaway, J., and Atanassov, P. (2004). Enzymatic biofuel cells for implantable and microscale devices. Chem. Rev. 104, 4867-4886. doi:10.1021/ cr020719k

Blanford, C. F., Foster, C. E., Heath, R. S., and Armstrong, F. A. (2009). Efficient electrocatalytic oxygen reduction by the 'blue' copper oxidase, laccase, directly attached to chemically modified carbons. Faraday Discuss. 140, 319-335. doi:10.1039/B808939F

Bourourou, M., Elouarzaki, K., Holzinger, M., Agnès, C., Le Goff, A., Reverdy-Bruas, N., et al. (2014). Freestanding redox buckypaper electrodes from multi-wall carbon nanotubes for bioelectrocatalytic oxygen reduction via mediated electron transfer. Chem. Sci. 5, 2885-2888. doi:10.1039/C3SC53544D

Bourourou, M., Elouarzaki, K., Lalaoui, N., Agnès, C., Le, G. offA., Holzinger, M., et al. (2013). Supramolecular immobilization of laccases on carbon nanotube electrodes functionalized with (methylpyrenylaminomethyl)anthraquinone for direct electron reduction of oxygen. Chemistry 19, 9371-9375. doi:10.1002/ chem. 201301043

Cheng, H., Yu, P., Lu, X., Lin, Y., Ohsaka, T., and Mao, L. (2013). Biofuel cell-based self-powered biogenerators for online continuous monitoring of neurochemicals in rat brain. Analyst 138, 179-185. doi:10.1039/C2AN36385B

Cinquin, P., Gondran, C., Giroud, F., Mazabrard, S., Pellissier, A., and Boucher, F. (2010). A glucose biofuel cell implanted in rats. PLoS ONE 5:e10476. doi:10.1371/journal.pone.0010476

Cosnier, S., Holzinger, M., Goff, A. L., and Zebda, A. (2010). Université Joseph Fourier - CNRS France patent number FR10.56672. 19 August 2010 extended PCT/FR10.56672/051931 (19/08/2010).

Cosnier, S., Le Goff, A., and Holzinger, M. (2014). Towards glucose biofuel cells implanted in human body for powering artificial organs: review. Electrochem. Commun. 38, 19-23. doi:10.1016/j.elecom.2013.09.021

Cracknell, J. A., Vincent, K. A., and Armstrong, F. A. (2008). Enzymes as working or inspirational electrocatalysts for fuel cells and electrolysis. Chem. Rev. 108, 2439-2461. doi:10.1021/cr0680639

Dai, H. (2002). Carbon nanotubes: synthesis, integration, and properties. Acc. Chem. Res. 35, 1035. doi:10.1021/ar0101640

Flexer, V., Brun, N., Destribats, M., Backov, R., and Mano, N. (2013). A novel threedimensional macrocellular carbonaceous biofuel cell. Phys. Chem. Chem. Phys. 15, 6437-6445. doi:10.1039/C3CP50807B
Flexer, V., and Mano, N. (2014). Wired pyrroloquinoline quinone soluble glucose dehydrogenase enzyme electrodes operating at unprecedented low redox potential. Anal. Chem. 86, 2465-2473. doi:10.1021/ac403334w

Forster, R. J., Walsh, D. A., Mano, N., Mao, F., and Heller, A. (2003). Modulating the redox properties of an osmium-containing metallopolymer through the supporting electrolyte and cross-linking. Langmuir 20, 862-868. doi:10.1021/ la035229h

Halámková, L., Halámek, J., Bocharova, V., Szczupak, A., Alfonta, L., and Katz, E. (2012). Implanted biofuel cell operating in a living snail. J. Am. Chem. Soc. 134, 5040-5043. doi:10.1021/ja211714w

Holzinger, M., Le Goff, A., and Cosnier, S. (2012). Carbon nanotube/enzyme biofuel cells. Electrochim. Acta 82, 179-190. doi:10.1016/j.electacta.2011.12.135

Hussein, L., Rubenwolf, S., von tetten, S. F., Urban, G., Zengerle, R., Krueger, M., et al. (2011). A highly efficient buckypaper-based electrode material for mediatorless laccase-catalyzed dioxygen reduction. Biosens. Bioelectron. 26, 4133-4138. doi:10.1016/j.bios.2011.04.008

Ivanov, I., Vidakovic-Koch, T., and Sundmacher, K. (2010). Recent advances in enzymatic fuel cells: experiments and modeling. Energies 3, 803-846. doi:10.3390/ en3040803

Jia, W., Valdés-Ramírez, G., Bandodkar, A. J., Windmiller, J. R., and Wang, J. (2013). Epidermal biofuel cells: energy harvesting from human perspiration. Angew. Chem. Int. Ed. 52, 7233-7236. doi:10.1002/anie.201302922

Katz, E., and MacVittie, K. (2013). Implanted biofuel cells operating in vivo methods, applications and perspectives - feature article. Energy Environ. Sci. 6, 2791-2803. doi:10.1039/C3EE42126K

Lalaoui, N., Elouarzaki, K., Le Goff, A., Holzinger, M., and Cosnier, S. (2013). Efficient direct oxygen reduction by laccases attached and oriented on pyrenefunctionalized polypyrrole/carbon nanotube electrodes. Chem. Commun. 49, 9281-9283. doi:10.1039/C3CC44994G

Lau, C., Adkins, E. R., Ramasamy, R. P., Luckarift, H. R., Johnson, G. R., and Atanassov, P. (2012). Design of carbon nanotube-based gas-diffusion cathode for $\mathrm{O} 2$ reduction by multicopper oxidases. Adv. Energy Mat. 2, 162-168. doi:10.1002/aenm.201100433

Leech, D., Kavanagh, P., and Schuhmann, W. (2012). Enzymatic fuel cells: recent progress. Electrochim. Acta 84, 223-234. doi:10.1016/j.electacta.2012.02.087

Little, S. J., Ralph, S. F., Mano, N., Chen, J., and Wallace, G. G. (2011). A novel enzymatic bioelectrode system combining a redox hydrogel with a carbon NanoWeb. Chem. Commun. 47, 8886-8888. doi:10.1039/C1CC11088H

Mano, N., Mao, F., and Heller, A. (2003). Characteristics of a miniature compartment-less glucose $/ \mathrm{O}_{2}$ biofuel cell and its operation in a living plant. J. Am. Chem. Soc. 125, 6588-6594. doi:10.1021/ja0346328

Meredith, M. T., Minson, M., Hickey, D., Artyushkova, K., Glatzhofer, D. T., and Minteer, S. D. (2011). Anthracene-modified multi-walled carbon nanotubes as direct electron transfer scaffolds for enzymatic oxygen reduction. ACS Catal. 1, 1683-1690. doi:10.1021/cs200475q

Meredith, M. T., and Minteer, S. D. (2012). Biofuel cells: enhanced enzymatic bioelectrocatalysis. Annu. Rev. Anal. Chem. 5, 157-179. doi:10.1146/annurev-anchem062011-143049

Miyake, T., Yoshino, S., Yamada, T., Hata, K., and Nishizawa, M. (2011a). Selfregulating enzyme-nanotube ensemble films and their application as flexible electrodes for biofuel cells. J. Am. Chem. Soc. 133, 5129-5134. doi:10.1021/ ja111517e

Miyake, T., Haneda, K., Nagai, N., Yatagawa, Y., Onami, H., Yoshino, S., et al. (2011b). Enzymatic biofuel cells designed for direct power generation from biofluids in living organisms. Energy Environ. Sci. 4, 5008-5012. doi:10.1039/C1EE02200H

Peigney, A., Laurent, C., Flahaut, E., Bacsa, R. R., and Rousset, A. (2001). Specific surface area of carbon nanotubes and bundles of carbon nanotubes. Carbon $N$. Y. 39, 507-514. doi:10.1016/S0008-6223(00)00155-X

Plumeré, N., Rüdiger, O., Oughli, A. A., Williams, R., Vivekananthan, J., Pöller, S., et al. (2014). A redox hydrogel protects hydrogenase from high-potential deactivation and oxygen damage. Nat. Chem. 6, 822-827. doi:10.1038/nchem.2022

Polsky, R., Brozik, S. M., Xiao, X., and Holland, J. T. (2001). Electrical "wiring” of enzymes. In: Webster JG, editor. Wiley Encyclopedia of Electrical and Electronics Engineering (New York: John Wiley \& Sons, Inc.). p. 1-18.

Rasmussen, M., Ritzmann, R. E., Lee, I., Pollack, A. J., and Scherson, D. (2012). An implantable biofuel cell for a live insect. J. Am. Chem. Soc. 134, 1458-1460. doi: $10.1021 / \mathrm{ja} 210794 \mathrm{c}$

Reuillard, B., Le, G. offA., Agnès, C., Holzinger, M., Zebda, A., Gondran, C., et al. (2013). High power enzymatic biofuel cell based on naphthoquinone-mediated 
oxidation of glucose by glucose oxidase in a carbon nanotube 3D matrix. Phys. Chem. Chem. Phys. 15, 4892-4896. doi:10.1039/C3CP50767J

Ronkainen, N. J., Halsall, H. B., and Heineman, W. R. (2010). Electrochemical biosensors. Chem. Soc. Rev. 39, 1747-1763. doi:10.1039/B714449K

Rubenwolf, S., Sané, S., Hussein, L., Kestel, J., von tetten, S. F., Urban, G., et al. (2012). Prolongation of electrode lifetime in biofuel cells by periodic enzyme renewal. Appl. Microbiol. Biotechnol. 96, 841-849. doi:10.1007/s00253-012-4374-8

Sales, F. C. P. F., Iost, R. M., Martins, M. V. A., Almeida, M. C., and Crespilho, F. N. (2013). An intravenous implantable glucose/dioxygen biofuel cell with modified flexible carbon fiber electrodes. Lab. Chip 13, 468-474. doi:10.1039/C2LC41007A

Samanta, D., and Sarkar, A. (2011). Immobilization of bio-macromolecules on selfassembled monolayers: methods and sensor applications. Chem. Soc. Rev. 40, 2567-2592. doi:10.1039/C0CS00056F

Sané, S., Jolivalt, C., Mittler, G., Nielsen, P. J., Rubenwolf, S., Zengerle, R., et al. (2013). Overcoming bottlenecks of enzymatic biofuel cell cathodes: crude fungal culture supernatant can help to extend lifetime and reduce cost. ChemSusChem 6, 1114-1114. doi:10.1002/cssc.201300520

Sané, S., Richter, K., Rubenwolf, S., Matschke, N. J., Jolivalt, C., Madzak, C., et al. (2014). Using planktonic microorganisms to supply the unpurified multi-copper oxidases laccase and copper efflux oxidases at a biofuel cell cathode. Bioresour. Technol. 158, 231-238. doi:10.1016/j.biortech.2014.02.038

Shaoa, M., Guschina, D. A., Kawahb, Z., Beyla, Y., Stoicaa, L., and Ludwig, R. (2014). Cellobiose dehydrogenase entrapped within specifically designed Os-complex modified electrodeposition polymers as potential anodes for biofuel cells. Electrochim. Acta 128, 318-325. doi:10.1016/j.electacta.2013.11.019

Smart, S. K., Cassady, A. I., Lu, G. Q., and Martin, D. J. (2006). The biocompatibility of carbon nanotubes. Carbon N. Y. 44, 1034-1047. doi:10.1016/j.carbon.2005. 10.011

Soukharev, V., Mano, N., and Heller, A. (2004). A four-electron $\mathrm{O}_{2}$-electroreduction biocatalyst superior to platinum and a biofuel cell operating at 0.88 V. J. Am. Chem. Soc. 126, 8368-8369. doi:10.1021/ja0475510

Southcott, M., MacVittie, K., Halámek, J., Halámková, L., Jemison, W. D., Lobel, R., et al. (2013). From "Cyborg" lobsters to a pacemaker powered by implantable biofuel cells. Energy Environ. Sci. 6, 81-86. doi:10.1039/C2EE23209J

Suraniti, E., Studer, V., Sojic, N., and Mano, N. (2011). Fast and easy enzyme immobilization by photoinitiated polymerization for efficient bioelectrochemical devices. Anal. Chem. 83, 2824-2828. doi:10.1021/ac200297r

Szczupak, A., Halámek, J., Halámková, L., Bocharova, V., Alfontac, L., and Katz, E. (2012). Living battery - biofuel cells operating in vivo in clams. Energy Environ. Sci. 5, 8891-8895. doi:10.1039/C2EE21626D

Valdés-Ramírez, G., Ya-Chieh, L., Kima, J., Jiaa, W., Bandodkara, A. J., and NuñezFlores, R. (2014). Microneedle-based self-powered glucose sensor. Electrochem. Commun. 47, 58-62. doi:10.1016/j.elecom.2014.07.014

Wen, D., Liu, W., Herrmann, A.-K., and Eychmüller, A. (2014). A membraneless glucose $/ \mathrm{O}_{2}$ biofuel cell based on Pd aerogels. Chemistry 20, 4380-4385. doi:10.1002/chem.201304635
Willner, B., Katz, E., and Willner, I. (2006). Electrical contacting of redox proteins by nanotechnological means. Curr. Opin. Biotechnol. 17, 589-596. doi:10.1016/ j.copbio. 2006.10 .008

Willner, I., Yan, Y.-M., Willner, B., and Tel-Vered, R. (2009). Integrated enzyme-based biofuel cells - a review. Fuel Cells 9, 7-24. doi:10.1002/fuce.200800115

Yahiro, A. T., Lee, S. M., and Kimble, D. O. (1964). Bioelectrochemistry: I. enzyme utilizing bio-fuel cell studies. Biochim Biophys Acta 88, 375-383. doi:10.1016/ 0926-6577(64)90192-5

Zayats, M., Willner, B., and Willner, I. (2008). Design of amperometric biosensors and biofuel cells by the reconstitution of electrically contacted enzyme electrodes. Electroanalysis 20, 583-601. doi:10.1002/elan.200704128

Zebda, A., Cosnier, S., Alcaraz, J. P., Holzinger, M., Le Goff, A., Gondran, C., et al. (2013). Single glucose biofuel cells implanted in rats power electronic devices. Sci. Rep. 3, 1516. doi:10.1038/srep01516

Zebda, A., Tingry, S., Innocent, C., Cosnier, S., Forano, C., and Mousty, C. (2011a). Hybrid layered double hydroxides-polypyrrole composites for construction of glucose $/ \mathrm{O}_{2}$ biofuel cell. Electrochim. Acta 56, 10378-10384. doi:10.1016/j. electacta.2011.01.101

Zebda, A., Gondran, C., Le, G. offA., Holzinger, M., Cinquin, P., and Cosnier, S. (2011b). Mediatorless high-power glucose biofuel cells based on compressed carbon nanotube-enzyme electrodes. Nat. Commun. 2, 370. doi:10.1038/ ncomms 1365

Zhang, J. E. (2008). PEM Fuel Cell Electrocatalysts and Catalyst Layers: Fundamentals and Applications. Heidelberg: Springer-Verlag GmbH.

Zhang, Q., Huang, J.-Q., Qian, W.-Z., Zhang, Y.-Y., and Wei, F. (2013). The road for nanomaterials industry: a review of carbon nanotube production, posttreatment, and bulk applications for composites and energy storage. Small 9, 1237-1265. doi:10.1002/smll.201203252

Conflict of Interest Statement: The authors declare that the research was conducted in the absence of any commercial or financial relationships that could be construed as a potential conflict of interest.

Received: 25 August 2014; accepted: 09 October 2014; published online: 24 October 2014.

Citation: Cosnier S, Holzinger $M$ and Le Goff A (2014) Recent advances in carbon nanotube-based enzymatic fuel cells. Front. Bioeng. Biotechnol. 2:45. doi: 10.3389/fbioe.2014.00045

This article was submitted to Bioenergy and Biofuels, a section of the journal Frontiers in Bioengineering and Biotechnology.

Copyright (C) 2014 Cosnier, Holzinger and Le Goff. This is an open-access article distributed under the terms of the Creative Commons Attribution License (CC BY). The use, distribution or reproduction in other forums is permitted, provided the original author(s) orlicensor are credited and that the original publication in this journal is cited, in accordance with accepted academic practice. No use, distribution or reproduction is permitted which does not comply with these terms. 